\title{
Impairment of Insulin-induced GLUT4 Translocation in Skeletal Muscle of KK-Ay Mouse, a Genetic Animal Model of Type 2 Diabetes
}

\author{
Toshihiro MIURA ${ }^{1)}$, Yasushi ITOH") and Torao IsHIDA ${ }^{2 y}$ \\ 'Department of Clinical Nutrition, Suzuka University of Medical Science, ${ }^{2} \mathrm{Hi}$-tech Research Center, Suzuka University of Medical Sci- \\ ence, 1001-1 Kishioka-cho, Suzuka, Mie, 510-0293, Japan,
}

(Received 17 September 2002; and accepted 20 November 2002)

\begin{abstract}
In skeletal muscle, insulin-induced glucose transport is known to start from the translocation of glucose transporter (GLUT) 4 from intracellular pool to plasma membrane. KK-Ay mouse, a genetic animal model of type 2 diabetes, develops moderate degrees of obesity and diabetes that are especially apparent in animals of more than 11 week old. Defect in insulin-induced GLUT4 translocation may also be involved in the geneses of type 2 diabetes mellitus. We examined the alteration of insulin-induced GLUT4 translocation in the skeletal muscle. After isolation of low density microsomal membrane and plasma membrane in skeletal muscle, insulin-induced translocation of GLUT4 in KK-Ay mouse were examined by Western blotting method. The insulin-induced translocation of GLUT4 from low density microsomal membranes to plasma membrane was significantly reduced in skeletal muscle of KK-Ay mice when compared with that in the ddY mice. These results support a view that the reduction of insulin-induced GLUT4 translocation in skeletal muscle may be involved in the deferioration of insulin sensitivity in diabetic KK-Ay mice.
\end{abstract}

Insulin resistance in skeletal muscle is known to be a predisposition and a feature in type 2 diabetes. Possible mechanisms involved in the insulin resistance have been investigated to gain further insight into the pathogenesis of the type 2 diabetes.

Various types of animal models have been adopted to elucidating human diabetic syndromes and the genetic factors, but we are still anticipating novel animal models having characteristics for explicating the complexities of diabetes. Mouse strains of spontaneous diabetes have previously been reported $(3,9,15)$, but, as each strain had a different process of the disease and the strains were not satisfactory for the study of the diabetes.

KK-Ay mouse train, a genetic type 2 diabetes model, develops moderate degrees of obesity and

Correspondence to: Dr Toshihiro Miura at above address.

Fax: $+81-593-83-9666$

Email: miura@suzuka-u.ac.jp diabetes as early as 11 week old. Phenotypic characterization revealed that the KK-Ay mouse had reduced insulin sensitivity (8). Skeletal muscles express glucose transporter (GLUT) 4 and have the unique machinery required for the movement of GLUT4 from intracellular pools to the plasma membrane (PM) $(6,17)$. The translocation process is induced by insulin and accounts for a significant part of the insulin action in peripheral tissues for maintaining glucose homeostasis. Defects in insulininduced GLUT4 translocation also contributes to characteristic of type 2 diabetes mellitus $(5,16)$. Although the exact molecular and cellular mechanism involved in insulin-stimulated GLUT4 translocation remains unclear, this process requires activation of phosphatidylinositol 3-kinase and serine/threonine phosphorylation events $(1,4,12,19,20)$.

In the present study, we examined the alteration of insulin-stimulated GLUT4 translocation in the skeletal muscle in order to further characterize this mouse model. 


\section{MATERIALS AND METHODS}

Animals. Male KK-Ay mice (11 weeks old, Clea, Japan) were kept in an experimental animal room for 1 weeks with free access to food and water. They were housed individually in an air-conditioned room at an ambient temperature of $22 \pm 2^{\circ} \mathrm{C}$ with a $12 \mathrm{~h}$ light-dark cycle.

Determination of Blood Glucose and Insulin. Blood samples were taken from the cavernous sinus with a capillary to determine blood glucose level. Five animals were used for each treatment group. Blood glucose levels were determined by the glucose oxidase method (18) and serum insulin was measured by radioimmunoassay using the double-antibody method (2).

Isolation of Hindlimb Muscle. The mice were given insulin $(0.5 \mathrm{U} / \mathrm{kg})$ subcutaneously and, $0.5 \mathrm{~h}$ later, the hindlimb muscle were resected for the experiment.

Low Density Microsome (LDM) and Plasma Membrane (PM) Fraction of Skeletal Muscle. The muscle tissue was placed in a buffer $(5 \mathrm{mM}$ sodium azide, $0.25 \mathrm{M}$ sucrose, $0.1 \mathrm{mM}$ phenylmethylsulfonyl fluoride (PMSF), $10 \mathrm{mM} \mathrm{NaHCO}_{3}$ (pH $7.0)$ ) at $4^{\circ} \mathrm{C}$. Subfractionation of muscle membrane was as described by Baron and colleagues (10) whose procedure was modified from that of Klip and colleagues $(7,11)$. The muscle was homogenized and was centrifuged at $1,000 \times g$ for 10 min, and the supernatant was saved. The resulting pellet was resuspended in the buffer and rehomogenized with glass homogenization tube. The supernatant was combined with the first supernatant, and centrifuged at $9,000 \times g$ for $10 \mathrm{~min}$. The resulting supernatant was then centrifuged at $190,000 \times g$ for $60 \mathrm{~min}$. These membranes were applied to a discontinuous sucrose gradient containing $25 \%, 30 \%$, and $35 \%$ sucrose (wt/vol) solutions and was centrifuged at $190,000 \times g$ for $16 \mathrm{~h}$. Membranes were collected atop each of sucrose gradients, resuspended in the buffer, pelleted by centrifugation at $190,000 \times g$ for $60 \mathrm{~min}$, and resuspended in the buffer.

Western Blot Analysis. The antibody used in the Western blotting (East Acres, USA) was raised against a synthetic peptide corresponding to the COOH-terminal domain of mouse GLUT4 (12 amino acid peptide), as reported by James et al. (13) (No reaction against brain, or liver. Does not cross- react with GLUT1 or GLUT2 tested). The membrane fractions $(0.1 \mathrm{mg})$ prepared were suspended in $1 \%$ SDS and $50 \mathrm{mM}$ dithiothreitol and subjected to SDS-polyacrylamide $(9 \%)$ gel electrophoresis. Electrophoretic transfer to nitrocellulose paper and detection of the immunocomplex with enhanced chemiluminescence (Amersham, Buckinghamshire, UK) were carried out as has been previously described (21). The sheet was exposed on RX X-ray film and intensifying screen (Fuji, Tokyo, Japan). Prestained molecular weight standard (Bio-Rad, Richmond, VA, USA) was used for estimation of the molecular weight.

Statistical Analysis. All data are expressed as mean $\pm_{\text {SEM. }}$. Paired and unpaired Student's $t$ test were used for the statistical analysis. Values were considered to be significantly different when $P$ value was less than 0.05 .

\section{RESULTS}

Blood Glucose and Insulin. As shown in Table 1, the body weight, blood glucose and insulin level in basal stage were significantly elevated in diabetic KK-Ay mice $(P<0.01)$.

Muscle GLUT4 Protein. Effects of exogenous insulin on muscle PM and LDM fraction of GLUT4 protein levels in KK-Ay mice are demonstrated in Fig. 1 The muscle PM protein levels in KK-Ay mice significantly decreased when compared with control ddY mice $(P<0.01)$. However, the muscle LDM levels did not change.

\section{DISCUSSION}

In this study, we analyzed GLUT4 levels in PM and LDM fractions of muscle to clarify the pathogenesis of the insulin resistance of type 2 diabetes in KK-Ay mice, and confirmed the results in the previous report (8). KK-Ay mouse exhibited obesity, hyperglycemia and hyperinsulinemia (Table 1). These results indicate that $\mathrm{KK}$-Ay mouse is an animal model of typical type 2 diabetes mellitus.

It has been known that glucose transporter GLUT4 translocates by insulin stimulation from a low density microsome membrane to the plasma membrane fraction, permitting the glucose entry into myocytes and adipocytes. Our study demonstrates that the KK-Ay mouse have a decrease in the insulininduced GLUT4 translocation in skeletal muscle.

Galuska et al. reported that genetic ablation of 
Table 1 Blood glucose and Insulin

\begin{tabular}{lcc}
\hline & Blood glucose $(\mathrm{mg} / \mathrm{dL})$ & Insulin $(\mu \mathrm{U} / \mathrm{mL})$ \\
\hline Normal mice & $164 \pm 11$ & $34 \pm 6$ \\
\hline KK-Ay mice & $526 \pm 20^{*}$ & $254 \pm 32^{*}$ \\
\hline
\end{tabular}

Each value represents the mean \pm SEM from 5 mice. Significantly different from normal mice, ${ }^{*} P<0.01$.
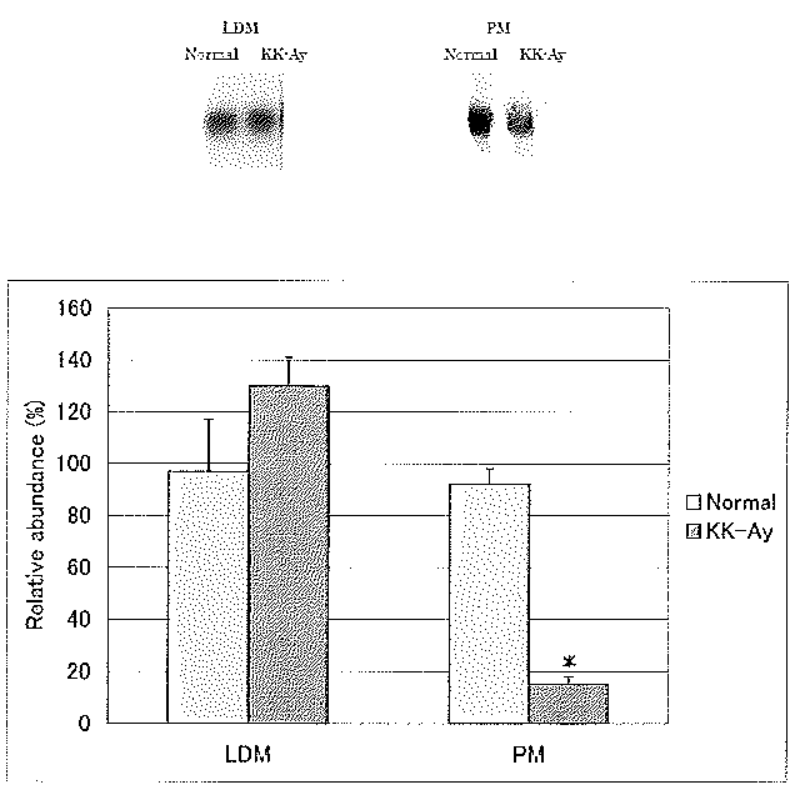

Fig. 1 Subcellular distribution of GLUT4 protein in insulin-stimulated muscle from KK-Ay mice. Plasma membrane (PM) and low density microsome (LDM) fractions from muscle treated insulin were prepared, and GLUT4 was Western blotted as described under Experimental Procedures. Quantitation of the amount of GLUT4 in intracellular fractions in muscle are shown. Values represent the results of the means and S.E. of five independent experiments. Significantly different from ddY, $* P<0.01$.

GLUT4 resulted in impaired insulin tolerance and in defect of glucose metabolism in skeletal muscle. It is also reported that overexpression of GLUT4 in muscle resulted in increased glucose uptake and metabolism, and protects against the development of insulin resistance in transgenic mice (16). These results indicate that the impairment of GLUT4 translocation results in the development of insulin resistance. Garvey et al. demonstrated that insulin alters the subcellular localization of GLUT4 vesicles in human muscle, and this effect was equally impaired in insulin resistant subjects with and without diabetes (6). They suggested that the defect in translocation was associated with abnormal accumulation of GLUT4 in a dense membrane compartment.

In conclusion, we showed that KK-Ay mouse exhibited the pattern of defects relavant to insulin resistance, and proposed that in GLUT4 translocation. The reduced insulin sensitivity in diabetic KK-Ay mice may be due, at least in part, to the impaired GLUT4 translocation by insulin in skeletal muscle.

\section{Acknowledgments}

This research was supported by Grant-in-Aid for Scientific Research from the Ministry of Education, Culture, Sports, Science and Technology (No. 14770610).

\section{REFERENCES}

1. Anai, M., Funaki, M., Ogihara, T., Kanda, A., Onishi, Y,, Sakoda, H. (1999) Enhanced insulin-stimulated activation of phosphatidylinositol 3-kinase in the liver of high-fat-fed rats. Diabetes, 48, 158-169.

2. Baron, A., Zhu, J. S., Zhu, J. H., Weldon, H., Maianu, L., Garvey, M. T. (1995) Glucosamine induces insulin resistance in vivo by affecting GLUT4 translocation in skeletal muscle. Implications for glucose toxicity. J. Clin. Invest., 98, 2792-2801.

3. Broinick, J. T., Etgen, G. J., Yaspelkis, B. B., and Ivy. J. L. (1994) Glucose uptake and GLUT4 protein distribution in skeletal muscle of the obese Zucker rat. Am. J. Physiol, 267, R236-R243.

4. Chen, H., Cong, L. N., Li, Y., Yao, Z. J., Wo, L., Zhang, Z. X. (1999) A phosphotyrosyl mimetic peptide reverses impairment of insulin-stimulated translocation of GLUT4 caused by overexpression of PTP1B in rat adipose cells. Biochemistry, 38, 384-389.

5. Galuska, D., Ryder, J., Kawano, Y., Charron, M. J., Zicrath, J. R. (1998) Insulin signaling and glucose transport in insulin resistant skeletal muscle. Special reference to GLUT4 transgenic and GLUT4 knockout mice. Adv. Exp. Med. Biol., 441, $73-85$.

6. Garvey, W. T., Maianu, L., Zhu, J. H., Brechtel-Hook, G, Wallace, P., Baron, A. D. (1998) Evidence for defects in the trafficking and translocation of GLUT4 glucose transporters in skeletal muscle as a cause of human insulin resistance. $J$. Clin. Invest., 101, 2377-2386.

7. James, D. E., Strube, M., Mueckler, M. (1989) Molecular cloning and characterization of an insulin-regulatable glucose transporter. Nature, 338, 83-87.

8. Kennedy, J. W., Hirshman, M. F., Gervino, E. V., Ocel, J. V., Forse, R. A., Hoenig, S. J. (1999) Acute exercise induces GLUT4 translocation in skeletal muscle of normal human subjects and subjects with type 2 diabetes. Diabetes, 48, 1192-1197.

9. King, P. A., Horton, E. D., Hirshman, M. F., Horton, E. S. (1992) Insulin resistance in obese Zucker rat (fa/fa) skeletal muscle is associated with a failure of glucose transporter translocation. J. Clin. Invest., 90, 1568-1575.

10. Klip, A., Ramlal, T., Young, D. A., Holloszy, J. O. (1987) 
Insulin-stimulated glucose transporters in rat hindlimb muscles. FEBS Lett., 224, 224-230.

11. Klip, A., Ramlal, T., Bilan, P. J., Cartee, G. D., Gulve, E. A., Holloszy, J. O. (1990) Recruitment of GLUT4 glucose transporter by insulin in diabetic rat skeletal muscle. Biochem. Biophys. Res. Commun., 172, 728-736.

12. Marks, V., Lloyd, K. (1963) Preservation of blood glucose analysis by glucose oxidase. Clin. Chem. Acta., 8, 326 .

13. Oka, Y., Asano, T., Shibasaki, A. (1990) Increased liver glucose transporter protein and mRNA in streptozotocin-induced diabetic mice. Diabetes, 39, 441-446.

14. Perez, C., Albert, I., DeFay, K. (1990) A nonsecretable cell surface mutant of tumor necrosis factor (TNF) kills by cell-tocell contact. Cell, 63, 251-258.

15. Sherman, W. M., Katz, A. L., Culter, C. L., Withers, R. T., Ivy, J. L. (1988) Glucose transport: locus of muscle insulin resistance in obese Zucker rats. Am. J. Physiol., 255, E374-E382.

16. Terauchi, Y., Tsuji, Y., Satoh, S., Minoura, H., Murakami, K.,
Okuno, A. (1999) Increased insulin sensitivity and hypoglycaemia in mice lacking the p85 alpha subunit of phosphoinositide 3-kinase. Nat. Genet., 21, 230-235.

17. Tirosh, A., Potashnik, R., Bashan, N., Rudich, A. (1999) Oxidative stress disrupts insulin-induced cellular redistribution of insulin receptor substrate-1 and phosphatidylinositol 3-kinase in 3T3-Ll adipocytes. A putative cellular mechanism for impaired protein kinase B activation and GLUT4 translocation. J. Biol. Chem, 274, 10595-10602.

18. Tsuura, Y., Ishida, H., Okamoto, Y., Tsuji, K., Kurose, T., Horie, M. (1992) Impaired glucose sensitivity of ATP-sensive $\mathrm{K}+$ channels in pancreatic B-cells in streptozotocin-induced NIDDM rats. Diabetes, 41, 861-865.

19. Zierath, J. R., Krook, A., Wallberg-Henriksson, H. (1998) Insulin action in skeletal muscle from patients with NIDDM. Mol. Cell Biochem., 182, 153-160.

20. Zorzano, A., Sevilla, L., Tomas, E., Camps, M., Guma, A., Palacin, M. (1998) Trafficking pathway of GLUT4 glucose transporters in muscle. Int. J. Mol. Med., 2, 263-271. 